\title{
Cataract Manifestation in Some Rare Inherited Diseases: A Narrative Review
}

\author{
Itzar Chaidir Islam ${ }^{1}$, Widya Natasya Asa'ad ${ }^{1,2}$, Najmatuzzahra ${ }^{1,3}$, \\ Annisa Mutmainnah Arifuddin ${ }^{4,5}$, Shafa Nabilah Arif ${ }^{6}$, \\ Zahra Aulia Magistriana Kasrum ${ }^{6}$, Hijriatun Nisa ${ }^{6}$, Rani Yunita Patong ${ }^{7}$ \\ ${ }^{1}$ Medical Education Department, Faculty of Medicine, Hasanuddin University, Makassar, Indonesia \\ ${ }^{2}$ Primaya Hospital, Makassar, Indonesia \\ ${ }^{3}$ Ananda Mother and Child Hospital, Makassar, Indonesia \\ ${ }^{4}$ Faculty of Medicine, Muslim Indonesia University, Makassar, Indonesia \\ ${ }^{5}$ Baruga Primary Health Center, Bantaeng, Indonesia \\ ${ }^{6}$ Medical Doctor Program, Faculty of Medicine, Hasanuddin University, Makassar, Indonesia \\ ${ }^{7}$ Pediatric Ophthalmology Division, Department of Ophthalmology, Faculty of Medicine, \\ Hasanuddin University, Makassar, Indonesia \\ Corresponding Author: Itzar Chaidir Islam
}

DOI: https://doi.org/10.52403/ijrr.20220159

\begin{abstract}
A congenital cataract is characterized by the opacity of the lens caused by genomic mutations. In this review, we discuss the correlation between genotype and phenotype of cataract formation in children with congenital abnormalities including Ayme-Gripp syndrome, Cockayne syndrome, Lowe's syndrome, Smith syndrome, and Vici syndrome.
\end{abstract}

Keywords: Congenital cataract, clinical manifestations, inherited syndrome.

\section{INTRODUCTION}

A cataract is a condition of cloudiness in the eye lens that occurs due to various intrinsic and extrinsic factors. This disease caused visual disturbances, especially in seeing objects precisely and in detail.(1) In clinical practice, cataracts can be found in the form of congenital cataracts, acquired cataracts, or age-related cataracts.(2) Cataracts develop due to structural or functional disturbances of lens proteins, resulting in an opacity. These events could happen as a result of stressors that occur both before and after birth. A significant proportion can be caused by mutations in some genes that encode lens proteins.(3)

\section{OBJECTIVES}

This paper aims to present an overview of the previous research and opinions about cataract formation, diagnostic assessment, and clinical therapy for inherited diseases. In this review, we also briefly discuss the correlation between genotype and phenotype of cataract formation in children with the focus of the discussion on molecular etiology of the disease.

\section{SEARCH STRATEGY}

In this article, we performed a search for the keywords "cataract", "pediatric cataract", "congenital cataract", "juvenile cataract", "genetic factor", and "inherited disease" on PubMed and Google Scholar databases (from January 2001 to December 2020). We mainly selected recent publications, but we also considered older critical articles. After selecting the search results and reviewing the article abstracts, we added proper papers with available full text into Mendeley ${ }^{\circledR}$ citation manager. After 
that, we have conducted a literature review with a total of 31 articles.

\section{RESULTS \\ CATARACT}

Cataract is defined as the clouding of the crystalline lens caused by a significant variation in the refractive index of the lens at distances close to the wavelength of the transmitted light. This change in refractive index can be caused by changes in the structure of the lens cells, changes in the protein constituents of the lens, or a combination of both. Cataracts are commonly associated with some micro disturbance of the lens structure. This disease also become the most common risk factor of blindness in both children and the elderly around worldwide.(4)

Blindness due to cataracts globally is a more common situation in populations with low socioeconomic status and developing countries. Cataract disease is classified into various types based on its morphology and time formation. There are three types of cataracts based on the morphological classification: subcapsular, nuclear, and cortical cataracts. In addition, this disease is also classified as age-related cataracts, Childhood cataracts, and Secondary cataracts. Age-related cataract was the most common type of cataract that formed in individuals after 50 years of age. Childhood cataracts were an opacity of the eye lens which is divided into congenital cataracts (present at birth) and juvenile cataracts (developing after childbirth) as a manifestation of genetic conditions, congenital disorders, or intrauterine infections. Secondary cataract was abnormalities due to eye trauma, disorders due to other eye diseases such as glaucoma or infection, disorders due to the toxicity of certain drugs or medical treatment (for example, corticosteroids and radiation exposure), or conditions due to associated systemic diseases.(5)

\section{CONGENITAL CATARACT}

A congenital cataract is a heterogeneous disease that occurs due to genetic etiology and environmental factors. This disease can occur separately or in association with other systemic disorders that occur in an individual child.(4) Currently, more than 115 genes have been reported as the cause of cataracts and continue to grow along with advances in cytogenetic analysis methods.(6)

Congenital cataract was the most significant causes of decreased vision or optical disturbances in children, characterized by unilateral or bilateral lens clouding without any precipitating factors. Inherited congenital cataracts have been reported to be formed after some changes in specific genes, either in crystalline structures, transmembrane transport proteins (including gap junction proteins and chaperons), or genes related to the development of transcription factors and the lens cytoskeleton. These abnormalities can be detected by various diagnostic techniques like targeted next-generation sequencing (NGS) and genome-specific cytogenetic analysis. Typically, mutations that cause severe damage to the protein will lead to congenital cataract formation, whereas milder variants only will increase the risk factor to become senile cataracts in the old ages. $(7,8)$

A meta-analysis study reported that approximately 2.4 out of 10,000 children in worldwide were born with congenital cataracts with varying degrees and patterns of lens opacity as its clinical manifestations.(9) In another study, the prevalence of children with cataract disease was reported to occur on 1-15/10,000 births. The underlying etiologic factors were genetic disorders, metabolic disorders, ocular trauma, and some were still idiopathic.(10)

Early diagnosis of hereditary cataracts will be very essential for patients and their families to underlie individualized genetic counseling and testing. The aim is to allow optimal child development during the 
early period of life and help patients and their families plan future prognosis. (3)

Early surgery and advanced correction in ophthalmology are essential to optimize visual acuity, maximize vision potential, and prevent amblyopia. Surgery in congenital cataracts is safer and more beneficial if performed at the age of 6 months or older. It is purposed to monitoring postoperative complications and optimize visual acuity. Although surgical management has been declared the best treatment for cataract cases, multidisciplinary approaches such as the collaboration of an ophthalmologist with pediatricians, orthoptists, and genetic counselors are also expected to provide a much better outcome.(11)

\section{INHERITED DISEASE RELATED TO CATARACT MANIFESTATION Aymé-Gripp syndrome}

The Ayme-Gripp Syndrome (AYGRP) is an established character by brachycephaly, an intellectual disability, sensorineural hearing loss, cataracts, cardiac anomalies, neurodevelopmental disorder, and skeletal limitation.(12) The pathogenic Mutation Annotation Format (MAF) of "C.161c > T, C.206C > G, CYP27A1" was discovered by transcription family factors in the N-terminus region and reported to be harmful by various in silico methods. MAF could be found in lens fiber cells during lens development, and homozygous MAF mutant mice proved defective differentiation of lens fiber cells, including crystallins. Whole-exome sequencing, with or without preliminary linkage analysis has reported some type of new cataract genes that has significant roles in PI3K/AKT/mTOR signaling, cholesterol production, or another pathomechanism within the last three years.(13)

By using comprehensive genomic testing, isolated pediatric cataracts were caused by 35 abnormalities in over 52 genes. Major inheritance was recorded caused by just 15 of these genes. Meanwhile, the minor inheritance was caused by just 7 of them. Cataracts in Ayme-Gripp Syndrome were mostly reported in the first year of life, but there are also findings that there are no problems in the eyes after seven years of age. Several studies reported that bilateral cataracts in this syndrome should be corrected surgically in two stages to prevent some secondary complications such as amblyopia, aphakia glaucoma, and complete blindness.(14)

\section{Cockayne syndrome}

Cockayne syndrome (CS) is a rare disease, first described by Edward Cockayne in 1936. Most of CS cases $(75 \%)$ are related to the mutant gene $(5 q 11)$, and $25 \%$ of patients are associated with the mutant ERCC8 or CKN2 gene (10q12). Both encode CSA and CSB proteins involved in DNA repair.(15) Changes caused by mutations can lead to the accumulation of damaged DNA, leading to cellular aging and change of cell growth. Therefore, the patient's death was interpreted as demyelination of the central and peripheral nervous system, leading to dysphagia, long-term chronic aspiration, multiple lung inflammations, and eventually extensive diffuse alveolar damage (16) In this sense, the causes of congenital cataracts are varied. Before considering certain types of genetic diseases, it is necessary to rule out the possibility of maternal infection during pregnancy. In addition, we should also investigate inborn errors of metabolism, such as galactosemia, which sometimes causes cataracts at birth. A careful clinical examination is essential to distinguish between congenital solitary cataracts and congenital cataract syndrome. There are two main categories in cataract syndrome: single gene disease and chromosomal disease (17).

According to previous studies, every baby with postnatal developmental delay, microcephaly, and the following two conditions: continuous cold hands and feet, bilateral hearing disturbance, photosensitive skin, tremor, joint contracture, and extreme weight loss, cataracts, and distinctive facial 
morphology should be suspected of CS case. By using these criteria, the doctor can improve the clinical recognition rate of CS to approximately $90 \%$.(18)

CS patients with complete bilateral cataracts require a multidisciplinary approach involving pediatrics and genetics. The total bilateral posterior capsule is the most common type of congenital cataract lesion in this syndrome. In addition, children with CS can also attend with enophthalmos, retinal dystrophy, strabismus, and nystagmus which would aggravate the vision loss. There is no implantation of intraocular lenses because patients with systemic diseases have a more intense inflammatory process and are at risk of complications such as glaucoma. Bilateral total cataract with posterior capsule metaplasia is common in patients with systemic syndrome.(19)

\section{Lowe's syndrome}

Ocular Cerebral Lowe's Renal Syndrome (OCRL), also known as Lowe's syndrome, is a rare congenital disease that could be marked by a triad of organ system diseases: eye diseases (such as neonatal cataracts and mental illnesses), neurological disease (retardation), and kidney dysfunction.(20) OCRL is caused by the disturbance of the oculocerebrorenal (OCRL1) gene at the Xq2426.1 site. OCRL1 is the primary phosphatidyl inositol-bisphosphate (PIP2) hydrolase in human proximal renal tubule cells. PIP2 has several function such as regulating intracellular signal transmission, transport of ions and substances across membranes, regulating the actin cytoskeleton, transcription, and membrane transport.(21) PIP2 is primarily found in skin fibroblasts, but its amount was drastically reduced in Lowe syndrome patients.(22)

According to studies on women with Lowe's syndrome, $94 \%$ of them can be diagnosed by slit-lamp examination due to significant white to grey mottled opacities in all layers of the lenticular cortex.(23) Prenatal diagnosis is based on enzyme activity detected in chorionic villi at 9-11 weeks or amniotic fluid cells at 15-20 weeks. At birth, bilateral cataracts and hypotonic ocular involvement can be seen in congenital infection (rubella), peroxisome disease, mitochondrial disease, myotonic dystrophy, or congenital myopathy (ocular muscular encephalopathy).(24)

The patient's management includes PCO eye surgery, body rehabilitation, bicarbonate, potassium, and vitamin D supplements. Early cataract removal is essential to avoid amblyopia. A regular eye examination can detect glaucoma early, allowing early treatment with glaucoma medications or trabeculectomy surgery. Metabolic disorders can be diagnosed and treated earlier, decreasing the mortality rate and morbidity.(25)

\section{Smith-Lemli-Opitz Syndrome}

Smith Lemli Opitz syndrome (SLOS) is an autosomal recessive disease that was presented in 1964 by three researchers. SLOS is associated with mutations in the 7-dehydrocholesterol reductase (7-DHCR) gene, resulting in decreased cholesterol biosynthesis.(26) Gene mutations in SLOS are identified by targeted genotyping. The most common mutation (1/3 of alleles in the mutant population) detected is c.964 1G> C (IVS81G>C), which results in the insertion of 134 base pairs. Children with SLOS who also have high 7-dehydrocholesterol (7DHC) / 8-dehydrocholesterol (8-DHC) and low serum cholesterol have many physical malformations, including cataracts.(27)

Congenital cataracts in SLOS are present in approximately $20 \%$ of cases and also develop in early age patients. The pathophysiology of postnatal cataract development in SLOS remains unclear. However, the reported cases of iris synechiae and capsular fibrosis by Donoghue S (2018) indicate that the development of cataracts may be accompanied by an inflammatory reaction (phacoanaphylaxis). The study also found that there may be a toxic effect in the lens 
caused by an increase in 7-DHC levels. This condition leads the capsule to rupture spontaneously, so there can be no posterior capsule and liquefaction of the lens cortex.(28)

\section{Vici Syndrome}

Vici syndrome (VICIS) is a recessively inherited disorder characterized by agenesis of the corpus callosum, cataracts, cardiomyopathy, oculocutaneous hypopigmentation, and combined immunodeficiency. This syndrome is caused by a mutation on chromosome $18 \mathrm{q} 12.3$ that encodes $\mathrm{P}$ granule protein 5 (EPG5), an autophagy regulator.(29) Most EPG5 mutations are distributed throughout the EPG5 coding sequence and are specific to the individual family, making it difficult to establish precise genotype-phenotype correlations. However, based on the survival time analysis until death or censorship date, it can be determined that patients with homozygous EPG5 mutations died at the median age of 9 months, whereas patients with heterozygous EPG5 mutations at the age of 48 months.(30) Neuroophthalmological features included retinal hypopigmentation, developmental delay, lower than average b-wave amplitudes on ERG, and possibly misrouting at the optic chiasm similar to typical albinism. Most patients with Vici syndrome have bilateral congenital cataracts. There were also optic atrophy and retinal changes in some patients, and a small number of patients had ocular albinism. (31)

\section{CONCLUSION}

Cataract features in five inherited diseases on this study showed a similar manifestation as bilateral opacity in the eye. Even these cases are rare, early diagnosis and prompt treatment were very essential to get an excellent management result. Surgical management is still the main choice of treatment, so the success outcome of its therapy will be determined by the presence or absence of complications.

\section{Acknowledgement: None}

\section{Conflict of Interest: None}

\section{Source of Funding: None}

\section{REFERENCES}

1. Haddeh Y. Review of Cataract Types and Its Pathogenesis In Patients Reviewing Al Moujtahd Hospital In Damascus, Syria. J Med Pharm allied Sci. 2018; (August 2018):1070-6.

2. Khokhar SK, Pillay G, Dhull C, Agarwal E, Mahabir M, Aggarwal P, et al. Pediatric cataract. BMC Ophthalmol. 2017;17(1):1.

3. Bell SJ, Oluonye N, Harding P, Moosajee $\mathrm{M}$. Congenital cataract: a guide to genetic and clinical management. Ther Adv Rare Dis. 2020;1:263300402093806.

4. Shiels A, Hejtmancik JF. Genetic origins of cataract. Arch Ophthalmol. 2007;125(2): 165-73.

5. Lam D, Rao SK, Ratra V, Liu Y, Mitchell P, King J, et al. Cataract. Nat Rev Dis Prim. 2015;1(June):1-2.

6. Berry V, Georgiou M, Fujinami K, Quinlan R, Moore A, Michaelides M. Inherited cataracts: Molecular genetics, clinical features, disease mechanisms and novel therapeutic approaches. $\mathrm{Br} \mathrm{J}$ Ophthalmol. 2020;104(10):1331-7.

7. Khan L, Shaheen N, Hanif Q, Fahad S, Usman M. Genetics of congenital cataract, its diagnosis and therapeutics. Egypt J Basic Appl Sci [Internet]. 2018;5(4):252-7. Available from: https://doi.org/10.1016/j.ejbas.2018.07.001

8. Shiels A, Hejtmancik JF. Biology of Inherited Cataracts and Opportunities for Treatment. Annu Rev Vis Sci. 2019;5:12349.

9. Wu X, Long E, Lin H, Liu Y. Prevalence and epidemiological characteristics of congenital cataract: A systematic review and meta-analysis. Sci Rep [Internet]. 2016;6(October 2015):1-10. Available from: http://dx.doi.org/10.1038/srep28564

10. Yi J, Yun J, Li ZK, Xu CT, Pan BR. Epidemiology and molecular genetics of congenital cataracts. Int $\mathrm{J}$ Ophthalmol. 2011;4(4):422-32.

11. Kim KH, Ahn K, Chung ES, Chung TY. Clinical outcomes of surgical techniques in 
congenital cataracts. Korean J Ophthalmol. 2008;22(2):87-91.

12. Amudhavalli SM, Gadea R, Gripp K. AuKline Syndrome Summary Genetic counseling. GeneReviews. 2020;Feb:1-2.

13. Alkhunaizi E, Koenekoop RK, Saint-Martin C, Russell L. Maternally inherited MAF variant associated with variable expression of Aymé-Gripp syndrome. Am J Med Genet Part A. 2019;179(11):2233-6.

14. Javadiyan S, Craig JE, Sharma S, Lower KM, Casey T, Haan E, et al. Novel missense mutation in the bZIP transcription factor, MAF, associated with congenital cataract, developmental delay, seizures and hearing loss (Aymé-Gripp syndrome). BMC Med Genet. 2017;18(1):1-6.

15. Wilson BT, Stark Z, Sutton RE, Danda S, Ekbote A V., Elsayed SM, et al. The Cockayne Syndrome Natural History (CoSyNH) study: Clinical findings in 102 individuals and recommendations for care. Genet Med. 2016;18(5):483-93.

16. Serranoa CA, Moránb V, A PD. Cockayne syndrome. Bol Med Hosp Infant Mex 2015;72(4)276-283. 2015;72(4):276-83.

17. Karikkineth AC, Scheibye-knudsen M, Fivenson E, Croteau DL, Bohr VA. Cockayne syndrome: Clinical features, model systems and pathways. Ageing Res Rev. 2018;(33):3-17.

18. Brodsky MC, Renaud DL. Pseudopapilledema in Cockayne syndrome. Am J Ophthalmol Case Reports [Internet]. 2021;22(September 2020):101035.

19. Trese MGJ, Nudleman ED, Besirli CG. Peripheral retinal vasculopathy in cockayne syndrome. Retin Cases Br Reports. 2017; 11(3):232-5.

20. Loi M. Lowe syndrome. Orphanet J Rare Dis. 2006;1(1):1-5.

21. Amirhakimi G, Fallahzadeh MH, Saneifard H. Lowe syndrome: Report of a case and brief literature review. Iran $\mathbf{J}$ Pediatr. 2009;19(4):417-20.

22. Bökenkamp A, Ludwig M. The oculocerebrorenal syndrome of Lowe: an update. Pediatr Nephrol. 2016;2201-12.

23. Sethi SK, Bagga A, Gulati A, Hari P, Gupta $\mathrm{N}$, Lunardi J. Mutations in OCRL1 gene in
Indian children with Lowe syndrome. Clin Exp Nephrol. 2008;12(5):358-62.

24. Maia ML de A, do Val MLDM, Genzani $\mathrm{CP}$, Fernandes FAT, de Andrade MC, Carvalhaes JT de A. Lowe syndrome: report of five cases. J Bras Nefrol orgão Of Soc Bras e Latino-Americana Nefrol. 2010;32(2):216-22.

25. Bonesi M, Rosa Loizzo M, Provenzano E, Menichini F, Tundis R. Anti-Psoriasis Agents from Natural Plant Sources. Curr Med Chem [Internet]. 2016;23(12):125067.

26. Malgorzata S, Nowaczyk JM. Smith-LemliOpitz Syndrome Summary. 2021;1-24.

27. Lazarin G, Haque I, Evans E, Goldberg J. Smith-Lemli-Opitz syndrome carrier frequency and estimates of in utero mortality rates. Prenat Diagn. 2017;37(4): $350-5$.

28. Donoghue SE, Pitt JJ, Boneh A, White SM. Smith-Lemli-Opitz syndrome: Clinical and biochemical correlates. J Pediatr Endocrinol Metab. 2018;31(4):451-9.

29. Waldrop MA, Gumienny F, Boue D, de los Reyes E, Shell R, Weiss RB, et al. Lowlevel expression of EPG5 leads to an attenuated Vici syndrome phenotype. Am J Med Genet Part A. 2018;176(5):1207-11.

30. Byrne S, Jansen L, U-King-im JM, Siddiqui A, Lidov HGW, Bodi I, et al. EPG5-related Vici syndrome: A paradigm of neurodevelopmental disorders with defective autophagy. Brain. 2016;139(3): 765-81.

31. Alotaibi M, Alotaibi Y, Alghamdi A, A Albadawi A. Vici syndrome: A rare autosomal recessive syndrome in Yamani infant. Biomed Genet Genomics. 2018;4(1): $1-3$.

How to cite this article: Itzar Chaidir Islam, Widya Natasya Asa'ad, Najmatuzzahra et.al. Cataract manifestation in some rare inherited diseases: a narrative review. International Journal of Research and Review. 2022; 9(1): 516-521. DOI: https://doi.org/10.52403/ijrr. 20220159 